\title{
Twelve month comparison of salmeterol and salbutamol as dry powder formulations in asthmatic patients
}

\author{
B Lundback, D W Rawlinson, J B D Palmer \\ on behalf of a European study group
}

\begin{abstract}
Background Salmeterol is a potent selective $\beta_{2}$ agonist that has been shown to have a duration of action in excess of 12 hours. In this study salmeterol and salbutamol were compared over a three month period with a further extension of nine months.

Methods Three hundred and eighty eight patients with mild to moderate reversible airways obstruction (forced expiratory volume in one second $\left(F E V_{1}\right)$ $>50 \%$ predicted) were randomised to receive salmeterol $(50 \mu \mathrm{g})$ twice daily or salbutamol $(400 \mu \mathrm{g})$ four times daily, both by dry powder, in a double blind parallel group study. During the first three months detailed assessment of efficacy was made with recording of morning and evening peak expiratory flow rates (PEF), asthma symptoms, and bronchodilator use when necessary for the relief of symptoms. Patients continued in the study for a further nine months with the salbutamol dose reduced to $400 \mu \mathrm{g}$ twice daily. Lung function was measured at the clinic and safety data were collected during this period.
\end{abstract}

Results Salmeterol produced a significantly higher mean morning PEF (mean difference compared with salbutamol 21 (95\% CI 12-31) $1 / \mathrm{min}$ ), and a significant reduction in mean diurnal variation in PEF (from $30 \mathrm{~V} / \mathrm{min}$ at baseline to 11 1/min during salmeterol compared with $34 \mathrm{l} / \mathrm{min}$ at baseline to $32 \mathrm{1} / \mathrm{min}$ during salbutamol treatment). Salmeterol also reduced day and night symptoms and use of rescue bronchodilator. $F E V_{1}$ increased with both salmeterol and salbutamol treatment over the 12 month treatment period. For both treatments the number of patients reporting exacerbations of asthma and the frequency of these exacerbations remained constant during the study. Thirty six patients in the salmeterol and 49 in the salbutamol group withdrew during the 12 months of the study.

Conclusions In this study salmeterol (50 $\mu \mathrm{g}$ twice daily) was more effective than salbutamol ( $400 \mu \mathrm{g}$ four times daily) in the control of asthma over three months, and more effective than salbuta- mol (400 $\mu$ g twice daily) over a further nine months. Neither salmeterol nor salbutamol was associated with any worsening of control of asthma.

(Thorax 1993;48:148-153)

$\beta_{2}$ Adrenoceptor agonists are established treatment for asthma for patients of all ages. They are effective bronchodilators and protect against various constrictor challenges such as exercise, cold air, methacholine, and histamine. ${ }^{1-4}$ The inhaled route is preferred as this delivers the drug directly to the lung and thus minimises potential systemic side effects. $^{5}$ The major drawback of currently available inhaled drugs is their short duration of action-namely, less than six hours. ${ }^{6}$ Salmeterol is a potent selective $\beta_{2}$ agonist that has a duration of action in excess of 12 hours in vitro and in vivo. ${ }^{8}$ In a four week parallel group study in 692 patients with mild to moderate asthma salmeterol increased morning and evening peak flow, reduced the variation in diurnal peak flow, reduced the requirement for additional salbutamol, and lessened symptoms by comparison with placebo. ${ }^{9}$

This study was designed to investigate the safety and efficacy of salmeterol $(50 \mu \mathrm{g})$ twice daily and salbutamol $(400 \mu \mathrm{g})$ four times daily, both as dry powders, in patients with mild to moderate reversible airways obstruction over a three month period. The double blind study continued for a further nine months with the salbutamol treatment group on a reduced dose of $400 \mu \mathrm{g}$ twice daily. During this period lung function was measured at the clinic and safety data were collected.

\section{Methods}

PATIENTS

The inclusion criteria required patients (aged 18 or over) to have a forced expiratory volume in one second $\left(\mathrm{FEV}_{1}\right)$ or mean daily peak expiratory flow rate (PEF; mean of the highest morning and evening measurements) greater than $50 \%$ predicted, an increase in $\mathrm{FEV}_{1}$ greater than $15 \%$ after taking $200 \mu \mathrm{g}$ inhaled salbutamol by a pressurised inhaler or $400 \mu \mathrm{g}$ inhaled salbutamol by a Diskhaler, a symptom score of 2 or more (for scale see 
Table 1 Asthma symptom scores

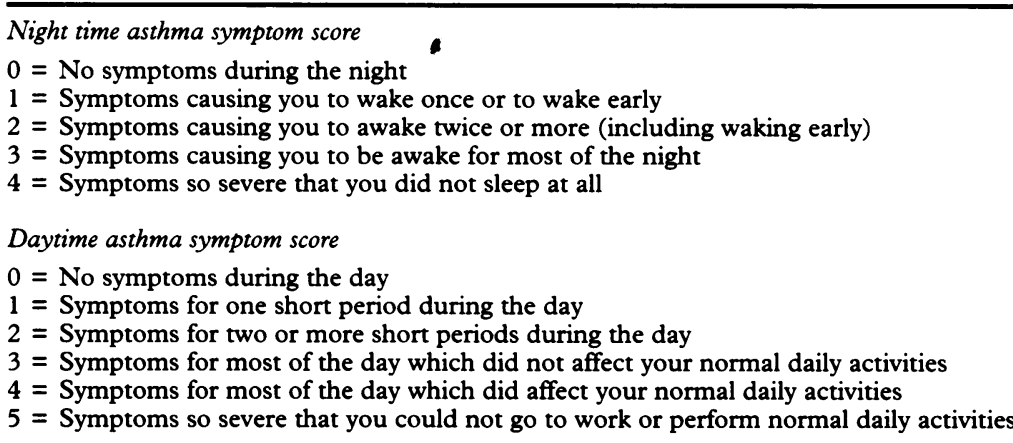

table 1), or a diurnal variation in PEF of at least $15 \%$ on four of the last seven days of the run in period. Patients who required $>20 \mathrm{mg}$ prednisolone were excluded. A total of 460 patients with a clinical history of mild to moderate reversible airways obstruction and no other serious medical conditions entered the run in period and of these 388 (table 2) were randomised to receive treatment (190 received salmeterol, 198 received salbutamol). The study was performed in 47 centres in 11 countries (see acknowledgements). All patients gave informed consent. Regulatory permission was obtained from all countries where it was required and approval from the appropriate ethics committee was obtained for all centres.

\section{STUDY MEDICATION}

The study was of a randomised, double blind, double dummy, parallel group design. There was a two week run in period in which patients took either salbutamol by pressurised inhaler or a salbutamol Diskhaler when necessary for the relief of symptoms. This same rescue medication was also available during the treatment period. After the run in period, patients were randomised for three months to salmeterol $(50 \mu \mathrm{g})$ twice daily and placebo four times daily or salbutamol $(400 \mu \mathrm{g})$ four times daily and placebo twice daily. During the final nine months patients received either salmeterol $(50 \mu \mathrm{g})$ twice daily or salbutamol

Table 2 Patients' characteristics

\begin{tabular}{lcc} 
& & \\
& $\begin{array}{c}\text { Salmeterol } \\
(50 \mu g \text { twice daily) }\end{array}$ & $\begin{array}{c}\text { Salbutamol } \\
(400 \mu g \text { four times a day) }\end{array}$ \\
\hline Number allocated to treatment & 190 & 198 \\
Men & $89(47)$ & $100(51)$ \\
Women & $101(53)$ & $98(49)$ \\
Median age (y) & 42 & 46 \\
$\quad$ Range & $19-79$ & $18-78$ \\
Median duration of asthma (y) & $10 \cdot 0$ & $11 \cdot 5$ \\
Mean PEF (1/min) (am/pm) & $367 / 397$ & $349 / 384$ \\
Mean FEV (l) & $2 \cdot 46$ & $2 \cdot 36$ \\
$\quad$ (\% predicted) & 76 & 73 \\
Smoking history: & & \\
Yes & $23(12)$ & $27(14)$ \\
No & $108(57)$ & $110(56)$ \\
Ex-smoker & $59(31)$ & $61(31)$ \\
Concurrent steroids & & \\
Inhaled only & $108(57)$ & $112(57)$ \\
Oral only & $7(4)$ & $11(6)$ \\
Inhaled and oral & $13(7)$ & $13(7)$ \\
\hline
\end{tabular}

$\%$ in parentheses
$(200 \mu \mathrm{g})$ twice daily under double blind, double dummy conditions.

\section{CONCOMITANT MEDICATION}

At the start of the run in period all oral, parenteral, rectal, or inhaled $\beta$ receptor agonists (other than the salbutamol inhaler provided), methylxanthines, and anticholinergic drugs were withdrawn. The patients continued inhaled corticosteroids (table 2), oral prednisolone ( $<20 \mathrm{mg}$ per day), sodium cromoglycate, nedocromil, or ketotifen at unchanged doses throughout the study. Short courses of increased inhaled or oral corticosteroids were allowed during exacerbations.

\section{PROTOCOI}

Patients attended the clinic on seven occasions during the first three months of the study with three further visits during the next nine months. At the first visit demographic details were recorded and blood samples were taken for biochemical and haematological analysis. Patients were given a daily record card to record their morning and evening PEF with a mini-Wright peak flow meter (before study or relief medication). They were asked to record their daytime and night time symptoms according to a scoring system (see table 1), and to note their use of rescue salbutamol. If patients met the inclusion criteria they entered the treatment phase. They were seen initially at intervals of two weeks for four weeks (visits 3, 4, and 5) and then every four weeks (visits 6 and 7) to three months.

The patients then continued a nine month safety phase with visits at three-monthly intervals (visits 8,9 , and 10). At each visit the physician recorded changes in medication; intercurrent illnesses, adverse events, and withdrawal and measured blood pressure, heart rate, and $F E V_{1}$ and forced vital capacity (FVC). Blood and urine samples were collected at all visits (except visit 4) and 12 lead electrocardiograms were recorded at visit 3 (before study treatment), visit seven (after three months), and visit 10 (after 12 months).

\section{POWER CALCULATION}

From results of our previous experience with salbutamol it was estimated that the residual standard deviation of mean morning or evening PEF was unlikely to exceed $45 \mathrm{l} / \mathrm{min}$. From this estimate of variability it was calculated that with 388 evaluable patients the study had a power of 0.91 to detect a mean difference in mean PEF between the two groups of $15 \mathrm{l} / \mathrm{min}$, assuming a two sided $t$ test and a $5 \%$ level of significance.

\section{ANALYSIS}

To be included in the analysis of a variable, patients must have provided at least four days of data for that variable during the run in period and data from at least half of the days in any period of assessment. The mean PEFs in the morning and evening were calculated for each patient together with the mean difference between salmeterol treatment and 
Figure 1 Changes in mean morning peak flow (PEF; left hand panel) and mean evening PEF (right hand panel) during 12

weeks of treatment with salmeterol ( $50 \mu \mathrm{g}$ twice daily; open circle) and salbutamol (400 $\mu \mathrm{g}$ four times daily; closed circle). Changes in morning PEF were significantly higher in patients taking salmeterol $(p<0.001)$.
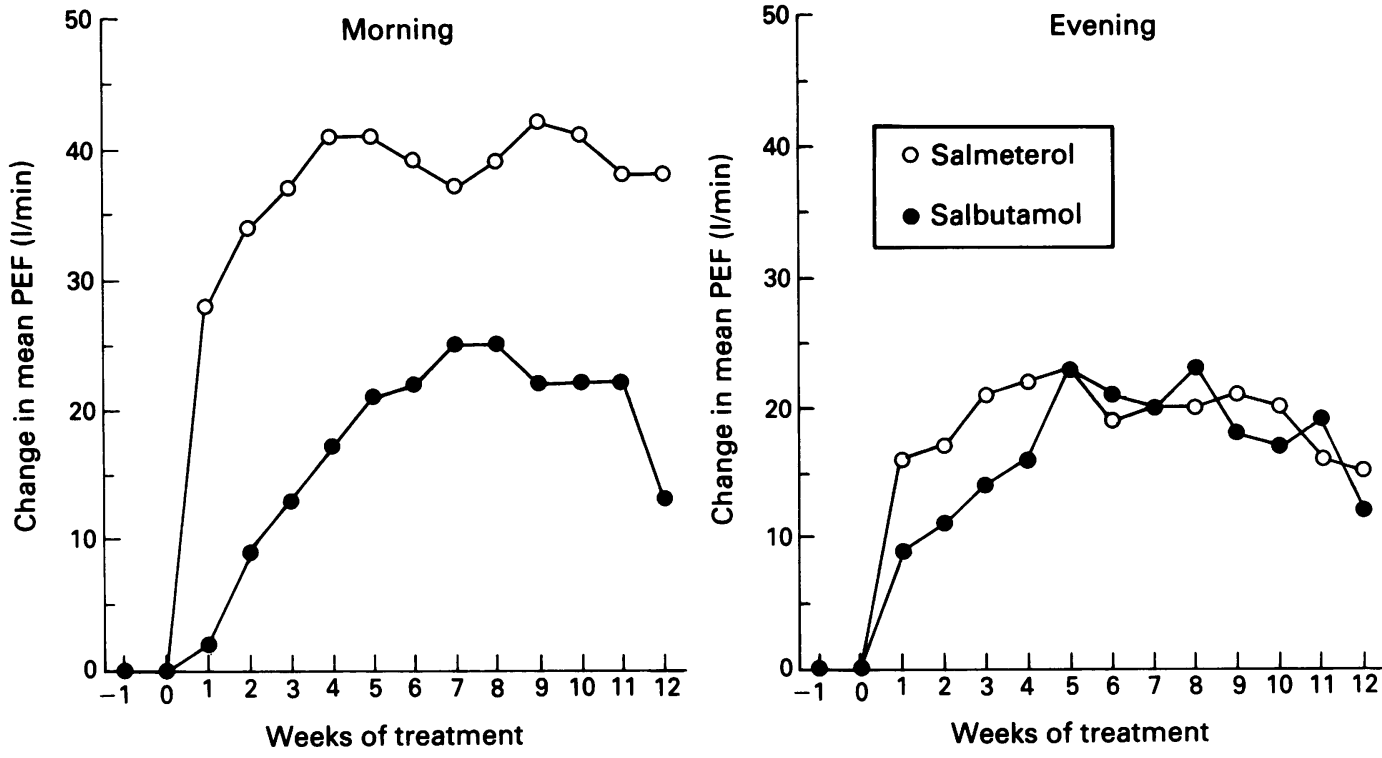

salbutamol treatment for these responses.

The mean values obtained during treatment were subjected to analysis of covariance with the mean values recorded in the second run in period as covariates. Changes in the proportion of nights with asthma score 0 , proportion of days with asthma score less than 2 , proportion of nights with no additional salbutamol, and proportion of days with no additional salbutamol were subjected to analyses of variance after transformation to ranks.

\section{Results}

Of the 388 patients who were randomised to treatment (190 salmeterol, 198 salbutamol) 303 patients (154 salmeterol, 149 salbutamol) completed the 12 months of treatment. Forty five patients were withdrawn during the three month treatment period ( 20 salmeterol, 25 salbutamol). The primary reasons for withdrawal were poor compliance with protocol (seven salmeterol, 10 salbutamol) or asth-

ma (seven salmeterol, eight salbutamol). The two treatment groups were well matched for demographic details, smoking habits, and duration and severity of their reversible airways disease (table 2). During the treatment period $57 \%$ of patients receiving salmeterol and $57 \%$ of patients receiving salbutamol also received inhaled corticosteroids.

Figure 1 shows the changes in mean morning and evening PEFs over the 12 weeks of treatment. Increase in mean morning PEF was significantly higher in patients taking salmeterol than in patients taking salbutamol ( $p<0.001)$; the mean difference was 21 $1 / \mathrm{min}(95 \%$ confidence interval $(95 \% \mathrm{CI})$ 12-31). Salmeterol also caused a significant reduction in the diurnal variation in PEF compared with salbutamol $(p<0.001)$; the mean variation was from $30 \mathrm{l} / \mathrm{min}$ at baseline to $11 \mathrm{l} / \mathrm{min}$ during salmeterol treatment compared with $34 \mathrm{l} / \mathrm{min}$ at baseline to $32 \mathrm{l} / \mathrm{min}$ during salbuterol treatment.

Figure 2 shows the weekly median percentage of nights with no symptoms of asthma.

Figure 2 Median \% of symptom free nights during 12 weeks' treatment with salmeterol ( $50 \mu \mathrm{g}$ twice daily; left hand panel) and salbutamol ( $400 \mu \mathrm{g}$ four times daily; right hand panel). The median value was significantly greater for patients taking salmeterol $(p<0.001)$

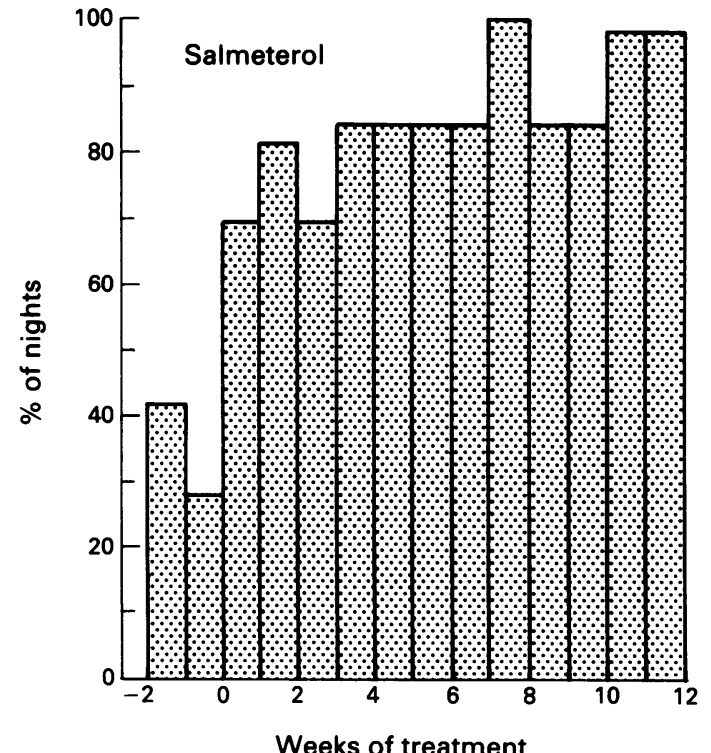


Figure 3 Median number of rescue doses of $\beta_{2}$ agonist taken during 12 weeks' treatment with salmeterol (50 $\mu \mathrm{g}$ twice daily; left hand panel) and salbutamol ( $400 \mu \mathrm{g}$ four times daily; right hand panel). The number of doses was significantly less for patients taking salmeterol $(p=0.013)$.

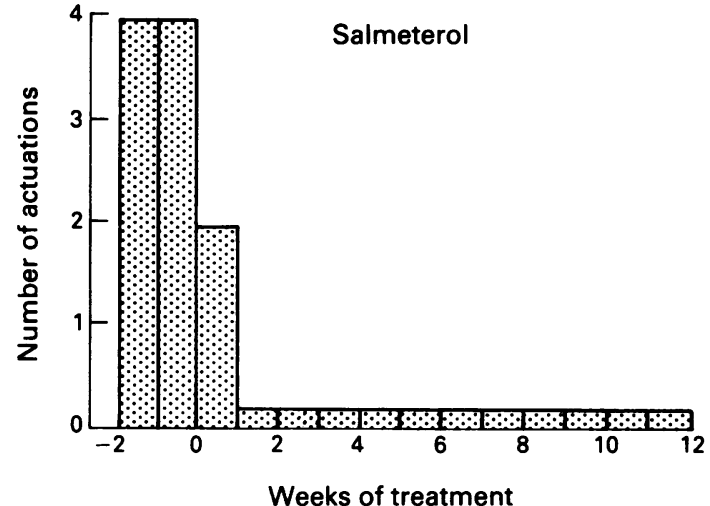

The number of nights with no symptoms was higher during salmeterol treatment than with salbutamol treatment $(p<0.001)$. Median values were $29 \%$ during the run in period for both groups. During treatment with salmeterol the median value increased to $100 \%$, and with salbutamol it increased to $71 \%$. Treatment with salmeterol was associated with significantly less use of rescue salbutamol during the day (fig 3 ). The median percentage of days when no additional salbutamol was used was zero for both groups during the run in period. During treatment with salmeterol the median value increased to $75 \%$ and during salbutamol treatment it increased to $67 \%(p=0.013)$. The percentage of nights when no additional salbutamol was used was also significantly lower in the salmeterol group than in the salbutamol group $(p<0.001)$. The percentage of nights when no salbutamol was used during the run in period was $43 \%$ for both groups. During salmeterol treatment the weekly median value increased to $86 \%$ after the first week of treatment and for the next 11 weeks of treatment it was $100 \%$. During treatment with salbutamol the median value increased to $86 \%$.

$\mathrm{FEV}_{1}$ increased with both salmeterol and salbutamol treatment over the 12 month treatment period (mean change for salmeterol varied from 0.23 to 0.281 and for salbutamol from $0 \cdot 1$ to $0 \cdot 151$ ). These changes were significantly greater for salmeterol at some but not all visits (see fig 4 ).

Both study drugs were well tolerated and

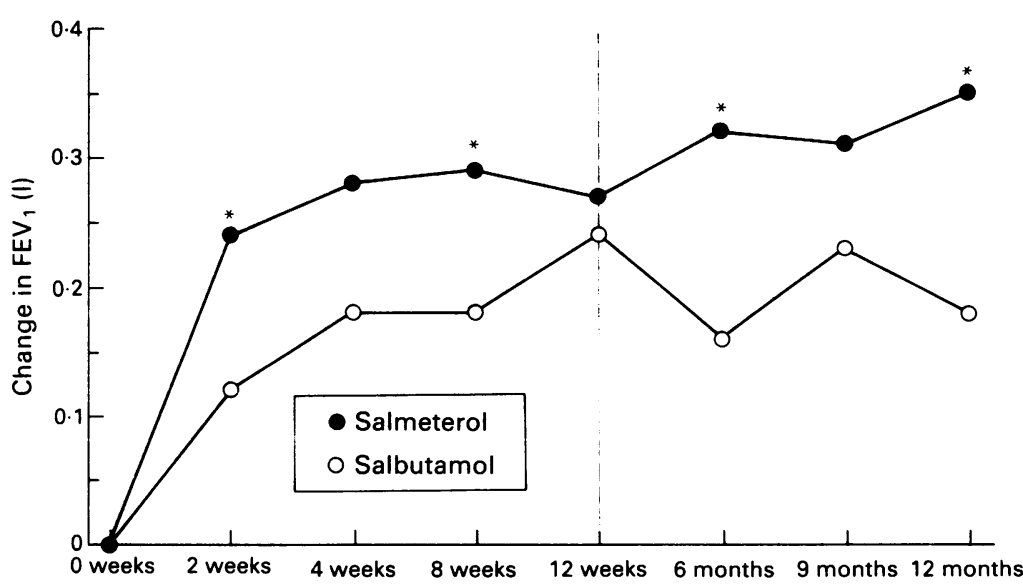

Figure $4 \mathrm{FEV}$, during 12 month' treatment with salmeterol (50 $\mu \mathrm{g}$ twice daily; closed circle) and salbutamol ( $400 \mu \mathrm{g}$ four times daily) for 12 weeks and $400 \mu \mathrm{g}$ twice daily for the last nine months (open circle). ${ }^{\star} p<0.05$.

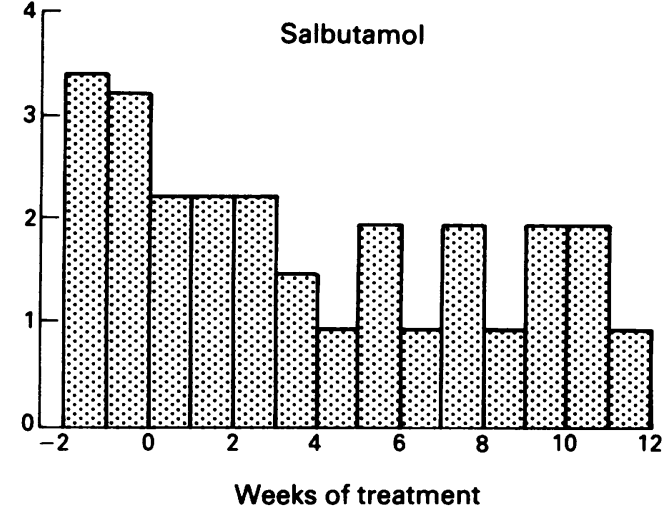

the overall incidence and nature of adverse events in the two groups were similar. The most commonly reported adverse event was exacerbation of asthma defined as episodes of acute asthma requiring additional or increased treatment other than relief $\beta_{2}$ agonists. Tables 3 and 4 show the number of patients with exacerbations of asthma and the frequency of exacerbations during each of the three monthly intervals for salmeterol and salbutamol respectively. The frequency of exacerbations was highest during the first three months of the study but this almost certainly reflects the greater frequency of study visits during this period. For both treatments the number of patients reporting exacerbations and the frequency of exacerbations did not increase during the last nine months of the study. This was also the case when the study population was subdivided into those not taking concomitant steroids, those taking inhaled steroids, and those taking oral steroids.

Table 3 Salmeterol: number of patients with asthma exacerbations during particular time intervals

\begin{tabular}{lrrrr}
\hline & \multicolumn{4}{c}{ Time interval (months) } \\
\cline { 2 - 5 } & $0-3$ & $3-6$ & $6-9$ & $9-12$ \\
\hline No of exacerbations: & 149 & 136 & 138 & 138 \\
0 & 29 & 19 & 15 & 18 \\
1 & 8 & 6 & 4 & 2 \\
2 & 2 & 1 & 3 & 0 \\
3 & 0 & 1 & 1 & 0 \\
4 & 1 & 1 & 0 & 0 \\
5 & 1 & 0 & 0 & 0 \\
10 & 190 & 164 & 161 & 158 \\
No of patients & 41 & 28 & 23 & 20 \\
No of patients with at & $(22 \%)$ & $(17 \%)$ & $(14 \%)$ & $(13 \%)$ \\
least one exacerbation & & & & \\
\hline
\end{tabular}

Table 4 Salbutamol: number of patients with asthma exacerbations during particular time intervals

\begin{tabular}{lrrrr}
\hline & \multicolumn{4}{c}{ Time interval (months) } \\
\cline { 2 - 5 } & $0-3$ & $3-6$ & $6-9$ & $9-12$ \\
\hline No of exacerbations: & 144 & 124 & 133 & 126 \\
0 & 36 & 26 & 22 & 20 \\
1 & 9 & 9 & 2 & 3 \\
2 & 6 & 1 & 1 & 2 \\
3 & 2 & 0 & 0 & 0 \\
4 & 1 & 1 & 0 & 0 \\
5 & 0 & 1 & 0 & 0 \\
6 & 0 & 0 & 1 & 0 \\
10 & 198 & 162 & 159 & 151 \\
No of patients & 54 & 38 & 26 & 25 \\
No of patients with at & $(27 \%)$ & $(23 \%)$ & $(16 \%)$ & $(17 \%)$ \\
least one exacerbation & & & & \\
\hline
\end{tabular}


Table 5 summarises the incidence of the pharmacologically predictable and most common $(>5 \%)$ adverse events for the first three months. There were no significant differences between the two groups. Twenty seven patients (12 receiving salmeterol, 15 receiving salbutamol) experienced serious adverse events requiring admission to hospital. Seventeen of these events involved exacerbations of asthma, of which seven occurred in patients receiving salmeterol and 10 in patients receiving salbutamol. One patient in the salbutamol group died as a result of a myocardial infarction, which was considered to be unlikely to be related to the study drug. There were also no significant changes in haematological and biochemical indices in either group and no significant changes were noted in heart rate, systolic and diastolic blood pressure, or 12 lead electrocardiograms.

\section{Discussion}

The data presented from this large multicentre clinical trial show that compared with salbutamol ( $400 \mu \mathrm{g}$ four times daily) salmeterol ( $50 \mu \mathrm{g}$ twice daily) produced significantly greater improvements in lung function, including a reduction in the diurnal variation of peak flow to a normal level. Also both the requirement for bronchodilator treatment to relieve symptoms and the symptoms of asthma during the day and night were reduced. These improvements occurred during the first week of treatment and were sustained throughout the 12 weeks of detailed study with no evidence of deterioration in control of asthma. Both treatments were well tolerated with a similar low incidence of adverse events in the two groups.

The study was continued for a further nine months with the patients receiving salbutamol at a lower frequency (twice daily). This facilitated the continued use of a double dummy technique to maintain blinding. During this extension the control of asthma as assessed by exacerbation rate and lung function at the clinic was maintained. The incidence of exacerbations of asthma in both groups was higher during the first three months (almost certainly as a result of the greater frequency of clinic visits), and then declined during the next nine months. Thus there was no evidence of waning control of asthma or decline

Table 5 Most common ( $>5 \%$ ) and pharmacologically predictable adverse events

\begin{tabular}{lll}
\hline & $\begin{array}{l}\text { Salmeterol } \\
(50 \mu g \text { twice daily) }\end{array}$ & $\begin{array}{l}\text { Salbutamol } \\
(400 \mu g \text { four times a day) }\end{array}$ \\
\hline No of patients & 190 & 198 \\
Asthma and related events & $29(15 \cdot 3)$ & $42(21 \cdot 2)$ \\
Acute nasopharyngitis & $12(6 \cdot 3)$ & $20(10 \cdot 1)$ \\
Respiratory and chest infections & $6(3 \cdot 2)$ & $12(6 \cdot 1)$ \\
Tremor & $2(1 \cdot 1)$ & $5(2 \cdot 5)$ \\
Tachycardia (noted by physician) & 0 & $3(1 \cdot 5)$ \\
Palpitations & $1(0 \cdot 5)$ & $3(1 \cdot 5)$ \\
Headache & $11(5 \cdot 8)$ & $6(3 \cdot 0)$ \\
Muscle cramp & $2(1 \cdot 1)$ & $3(1 \cdot 5)$ \\
\hline
\end{tabular}

$\%$ in parentheses. in lung function as has been reported recently in patients having regular $\beta_{2}$ agonist treatment ${ }^{1011}$ Although this is reassuring there was no placebo group having treatment for relief of symptoms only for comparison and therefore further studies are required to answer the question over the long term safety of regular $\beta_{2}$ agonist treatment. This sustained control of asthma was achieved despite the fact that $40 \%$ of the patients were not receiving concurrent inhaled glucocorticosteroids. At the outset of this study it was considered appropriate to relate salmeterol to an active comparator given at its recommended regular dosage. Direct comparisons in adults in challenge studies between salmeterol and salbutamol, both administered as dry powders, have not been reported. Salmeterol $(50 \mu \mathrm{g})$ given as a dry powder or metered dose aerosol, however, gave equal protection against histamine challenge ${ }^{12}$ and salbutamol $(200 \mu \mathrm{g})$ by metered dose aerosol gave acute protection equivalent to that of salmeterol ( $50 \mu \mathrm{g}$ by metered dose aerosol) in most but not all ${ }^{12}$ challenge studies. ${ }^{13-16}$ Salbutamol given as $200 \mu \mathrm{g}$ by metered dose aerosol has been shown to be equivalent to salbutamol given as $400 \mu \mathrm{g}$ of dry powder. ${ }^{17}$ We therefore believe that this dose of salbutamol would give an acute effect roughly equal to that of salmeterol $(50 \mu \mathrm{g})$ although the effect would not be maintained for the same length of time. The change in the dose of salbutamol from four times to twice daily after three months was to aid continued compliance. During the final nine months lung function was measured at the clinic at regular intervals and this was usually in the morning so the maintained effect of salbutamol is to be expected.

Thus salmeterol given either as a dry powder or by metered dose aerosol ${ }^{18}$ is an effective treatment for asthma over at least 12 months compared with salbutamol.

We express thanks for assistance with the study to $\mathrm{Dr} N$ Vetter and Dr H Zwick (Austria), Dr R Cordier and Dr Deman (Belgium), Dr P Faurschou, Dr O Davidsen, Dr U G Svendsen, and Dr B Weeke (Denmark), Dr J Kotaniemi and Dr M I lavu (Finland) Dr Balgaries, Dr Lebas, and Dro Dr M Havu (Finland), Dr Balgaries, Dr Lebas, and Dr de Muizon (France), Dr D-H Mahlo, Dr M Kaeppel, Dr Ebeling, Dr T Koumba, Dr N Scheffler, Dr H P Brackmann and Dr H L Hahn (Germany), Professor E A Pastorello and Professor Bruno (Italy), Dr P Mendes and Dr F Ribeiro (Portugal), Dr P O Rydström, Dr D Huberman, Dr K Osterman, Dr J Boe, Dr B-A Hermansson, Dr G Wikman, D Y Homblad, Dr J Ankerst, Dr L Grettve, Dr O Robertsson, Dr J Kiviloog, Dr B Lundback, Dr Granstrom, Dr Persson, and Dr Nemcek (Sweden), Dr J M Tschopp, Dr O Brandli, and Dr Rochat (Switzerland), Dr R Clark, Dr R Dent, Dr M $G$ Britton, Dr J Siddorn and Dr J A McM Turner (United Kingdom).

Clark TJH. Choices of drug treatment in asthma Pharmacol Ther 1982;17:221-8.

2 McFadden ER Jr. Aerosolized bronchodilators and steroids in the treatment of airways obstruction in adults. Am Rev Respir Dis 1980;122:89-96.

3 Svedmyr N, Lofdahl CG. Physiology and Pharmacodynamics of beta-adrenergic agonists. In: Jenne JW, Murphy S, eds. Drug therapy for asthma. New York: Murphy S, eds. Drug therapy for asthma. New York:
Dekker, 1987:177-212.

4 Tattersfield AE. Bronchodilator drugs. Pharmacol Ther 1982;17:299-313.

5 Larsson S, Svedmyr N. Bronchodilating effect and side effects of $\beta_{2}$-adrenoceptor stimulants by different modes of administration (tablets, metered aerosol and combifations therafol A study with salbutamol in as combiAm Rev Respir Dis 1977;116:861-9. 
6 Svedmyr N. Anti-asthma xanthines and adenosine. In: Andersson KE, Persson CGA, eds. Current clinical practice. Series No 19. Amsterdam; Excerpta Medica, practice. Series

7 Svedmyr N. Fenoterol: A beta ${ }_{2}$-adrenergic agonist for use in asthma. Pharmacol Ther 1985;5:109-26.

8 Ball DI, Brittain RT, Coleman RA, Denyer LH, Jack D, Johnson $\mathrm{M}$, et al. Salmeterol, a novel, long-acting $\beta_{2^{-}}$ adrenoceptor agonist: characterization of pharmacological activity in vitro and in vivo. Br $\mathcal{F}$ Pharmacol 1991 ; 104:665-71.

9 Dahl R, Earnshaw JS, Palmer JBD. Salmeterol: a four week study of a long-acting beta-adrenoceptor agonis for the treatment of reversible airways disease. Eur Respir f 1991;4:1178-84.

10 Sears MR, Taylor RD, Print CG, Lake DC, Li Q Flannery EM, et al. Regular Inhaled beta-agonist treatment in bronchial asthma. Lancet 1990;336:1391-6.

11 van Schayck CP, Dompeling E, van Herwaarden CL. Bronchodilator treatment in moderate asthma or chronic bronchitis: continuous or on demand? $B M F$ 1991;303:1426-31.

12 Campos Gongora H, Antoni F, Wisniewski Z, Tattersfield A. A single-dose comparison of inhaled albuterol and two formulations of salmeterol on airwity reactivity in asthmatic subjects. Am Rev Respir Dis 1991;144:626-9.
13 Taylor IK, O'Shaughnessy KM, Choudry NB, Adachi M Palmer JBD, Fuller RW. A comparative study in atopic subjects with asthma of the effects of salmeterol and salbutamol on allergen-induced bronchoconstriction, increase in airway reactivity, and increase in urinary leukotriene $\mathrm{E}_{4}$ excretion. F Allergy Clin Immunol 1992; 82:575-83.

14 Anderson SD, Rodwell LT, Du Toit J, Young IH. Duration of protection by inhaled salmeterol in exercise-induced asthma. Chest 1991;100:1254-60.

15 Malo JL, Ghezzo H, Trudeau C, L'Archeveque J, Cartier A. Salmeterol, a new inhaled beta ${ }_{2}$-adrenergic agonist, has a longer blocking effect than albuterol on hyperventilation-induced bronchoconstriction. $\mathcal{f}$ Allergy Clin Immunol 1992;89:567-74.

16 Pauwels R, Derom E. Salmeterol's early clinical development and challenge studies. European Respiratory Review 1991;1:261-4.

17 Mathieu M, Goldman M, Lellouche N, Sartene R. Kinetics of action of salbutamol inhaled from a metered dose inhaler (MDI) and a 'diskhaler'. Eur $\mathcal{f}$ Clin Pharmacol 199242:435-8.

18 Britton MG, Earnshaw JS, Palmer JBD. A twelve-month comparison of salmeterol with salbutamol in asthmatic patients. Eur Respir f 1992;5:1062-7. 